\title{
AS CIÊNCIAS NATURAIS \\ E AS CIÊNCIAS DO ESPÍRITO \\ NA ERA DA GLOBALIZAÇÃO*
}

Walter Jaeschke**

RESUMO - Neste artigo, o autor apresenta, primeiramente, reflexões de cunho histórico sobre a relação entre as Ciências Naturais e as Ciências do Espírito, seguidas de observações, de caráter mais sistemático, sobre o conceito das próprias Ciências do Espírito. Com fundamento nessas observações, tece algumas reflexões sobre até que ponto podemos esperar da globalização efeitos sobre as Ciências Naturais e as Ciências do Espírito.

PALAVRAS-CHAVE - Ciências Naturais. Ciências do Espírito. Globalização.
ABSTRACT - In this article, the author presents, firstly, reflections of historical character about the relationship between natural sciences and human sciences. Remarks of more systematic character on the very concept of human sciences follow those reflections. Grounded on such observations, the author discusses possible effects of globalization upon human sciences and natural sciences as well.

KEY WORDS - Natural sciences. Human sciences. Globalization.

Permitam-me iniciar minha conferência com a confissão de uma 'deformação', talvez 'típica para um representante das Ciências do Espírito': a saber, a confissão de que o tema que me foi proposto, "Ciências Naturais e Ciências do Espírito na era da globalização", nem poderia ser tratado sem antes formular e responder à pergunta pela relação entre as duas ciências até agora, na antecâmara dos processos que denominamos, há não muito tempo, com a palavra vaga "globalização". Afinal de contas, nunca existiu uma fórmula fixa, compartilhada por todas as pessoas, para descrever de forma cogente a relação entre as Ciências Naturais e as Ciências do Espírito, que hoje só precisaria ser recapitulada e desenvolvida com vistas à deixa "globalização". O simples discurso sobre "Ciências Naturais e Ciências do Espírito" sempre foi controvertido, sempre foi matéria controvertida - e

* Optei por traduzir "Naturwissenschaften" por "Ciências Naturais" e "Geisteswissenschaften", não pelo seu equivalente usado no Brasil, "Ciências Humanas", mas pelo equivalente literal "Ciências do Espírito", que soa rebarbativo em português, mas é necessário, por razões inerentes à argumentação desenvolvida pelo autor, no decorrer do trabalho [nota do Tradutor]. Traduzido por Peter Naumann

** Professor da Universidade de Bochum, Alemanha.

\begin{tabular}{|l|l|l|l|l|l|}
\hline VERITAS & Porto Alegre & v. 51 & n. 1 & Março 2006 & p. 121-132 \\
\hline
\end{tabular}


isso por razões muito distintas. Mas ele tem relevância para a resposta à pergunta, como essas ciências e talvez também a sua relação se redimensionam sob as condições da "globalização". E mesmo essa deixa da "globalização" não pode ser embolsada simplesmente como moeda corrente, para ser gasta novamente. Tratase aqui de um processo altamente complexo, cuja especificidade - à diferença de épocas anteriores, nas quais podemos encontrar fenômenos similares (mas, precisamente, apenas similares) - somente estamos começando a compreender paulatinamente, cuja forma de percurso entrementes descrevemos em algumas poucas áreas e em períodos bem-delimitados, e cujos efeitos ainda não podemos minimamente apreciar em panorama e, mais ainda, praticamente nem podemos intuir.

Diante dessas múltiplas incertezas parece-me imprescindível iniciar com duas partes preparatórias: uma observação de cunho mais histórico sobre a relação entre as Ciências Naturais e as Ciências do Espírito (I) e uma segunda observação, de caráter mais sistemático, sobre o conceito das próprias Ciências do Espírito (II). Com fundamento nessas observações, pretendo, depois, arriscar - com a devida cautela - algumas reflexões sobre até que ponto podemos esperar da globalização efeitos sobre as Ciências Exatas e Humanas (III).

\section{Sobre a relação entre as Ciências Naturais e as Ciências do Espírito}

Já há mais de um século se fala sobre a relação entre as Ciências Naturais e as Ciências do Espírito - e não se fala apenas, mas se litiga. Por um lado, esse litígio não deixou de produzir seus resultados, à medida que elucidou as implicações dessa relação. Por outro, ele não conduziu a um resultado universalmente compartilhado, e não necessitamos de nenhuma coragem para formular o prognóstico de que, em tempo previsível, também não será tomada uma decisão definitiva. Esse litígio apresenta conjunturas distintas no seu percurso; transcorre sob auspícios cambiantes e também com êxito mutante, embora nunca retumbante. Controvertidas são, por um lado, a estruturação dual do cosmos da ciência e, por outro lado, a pergunta sobre como tal dualidade - caso ela pudesse ser suposta com razão - deveria ser determinada em termos de conteúdo e terminologicamente. Assim essa relação, que define os contornos da paisagem científica contemporânea, possui menos o estatuto de um resultado de processos históricos: é o resultado efetivo, mas perfeitamente controvertido de uma compreensão e cultura da ciência, tal como elas se formaram sucessivamente, há cerca de três séculos, consolidando-se no limiar do século XIX até ao meio desse mesmo século - num processo marcado tanto por contingências quanto por leis. O racionalismo do século XVIII ainda desconhecia a dualidade de Ciências Naturais e Ciências do Espírito. Muito do que hoje se apresenta como "Ciência Humana" - assim, e.g., a Historiografia - ainda era considerado "arte" - no sentido da téchne grega -, ficando assim excluído da ciência, cujo traço distintivo era a demonstração rigorosamente racional. Naquela época, a correspondência mais próxima à dualidade mais recente de Ciências Naturais e Ciências do Espírito era essa diferença entre 
"arte" e "ciência" - e esta última, definida pelo seu caráter racional, pode ser representada integralmente num "sistema". Por volta de 1800, na época da filosofia clássica alemã, essas "artes" adquiriram o estatuto de ciência, embora não como ciências individuais isoladas; foram incluídas num unitário "sistema da ciência”, que se caracteriza pelo fato de abarcar um grande número de disciplinas científicas individuais e colocá-las num nexo sistemático abrangente, em meio ao qual elas podiam desenvolver a sua forma peculiar. Atribuiu-se às ciências individuais até uma perfectibilidade infinita, sem consideração da suposição de que o abrangente "sistema das ciências" já tinha sido concluído e consumado. Para o conceito enfático da ciência, que sustenta esse projeto, a distinção entre "Ciências Naturais" e "Ciências do Espírito" ainda não passava a ser um problema. Temia-se aqui uma dupla ameaça da unidade da ciência: primeiramente, em virtude do regressus in infinitum, nos empreendimentos de fundamentação, em segundo lugar, em virtude de uma multiplicidade não mais racionalmente controlável. Por isso afigurou-se na época como tarefa genuína da filosofia evitar, por meio da fundamentação convincente de todo o conhecimento, que um desses dois modos de ausência de fundamento do conhecimento se tornasse realidade - pois, caso a fundamentação do conhecimento fracassasse, a nossa ciência "não [seria] um prédio uno e coerente, mas um agregado de cômodos, sendo impossível passar de um para outro; seria uma habitação na qual nos perdemos sempre e nunca nos sentimos em casa. Não haveria luz nela, e remanesceríamos pobres, apesar de todas as nossas riquezas". ${ }^{1}$ Poucas décadas mais tarde, esse prognóstico sombrio, formulado no condicional, já se tornaria realidade do conceito moderno, fraco, de ciência - sem que, porém, a sensação pouco confortável transmitida pelo cenário, abominado por volta de 1800, ainda fosse percebida genericamente como inadequada, pois, na primeira metade do século XIX, ocorreu um processo tempestuoso de diferenciação das ciências individuais, ao qual se vincularia genericamente uma profunda transformação da compreensão de ciência. A "ciência” paradigmática não é mais o "sistema da ciência", que consegue integrar as ciências individuais, mas ao mesmo tempo se distingue marcantemente delas, mas justamente a própria disciplina individual. Agora, a sua inserção num "sistema abrangente da ciência" não é nem uma das condições do seu êxito nem uma das condições da sua autocompreensão.

Descoladas as ciências individuais de uma ciência unitária, denominada "ciência" no sentido enfático desse termo, tal situação demandou novos princípios classificatórios. Ela ensejou a formação da dualidade de Ciências Naturais e Ciências do Espírito, mas a tentativa do positivismo de renovar, nesse novo fundamento, sob condições alteradas, a idéia da "ciência unitária", é igualmente característica. Por isso, a insistência na estrutura dual do cosmos científico, na dualidade nunca se reveste do caráter meramente neutro da descoberta de um novo estado de coisas [Sachverhalt], mas sempre é simultaneamente um momento na rejeição

1 Johann Gottlieb Fichte. Über den Begriff der Wissenschaftslehre, in: Fichte. Edição completa da Academia de Ciências da Baviera, Seção. I, vol. 2., p. 116 s.,124 s. 
conflitiva de uma concepção de ciência dominada pelas Ciências Naturais, resultando do temor fundamentado diante da exclusão das agora assim chamadas "Ciências do Espírito" da gama das ciências em geral. Com vistas ao positivismo do final do século XIX, isso vale tanto quanto para o neopositivismo do século XX. A afirmação da diferença dos dois ramos da ciência baseia-se na afirmação de uma diferença de método entre eles: entre as Ciências Naturais, enquanto ciências "explanatórias" ou "ciências nomotéticas", empenhadas na revelação das leis subjacentes e na identificação do universal, e as Ciências do Espírito, enquanto ciências "compreensivas" ou "ciências ideográficas", isto é, ciências empenhadas em apreender o individual no seu caráter peculiar. Ocorre que a diferença entre "explicar" e "compreender" não é tão fecunda como provavelmente seria desejável; além disso, ela não pode ser mantida com precisão no plano terminológico nem no idioma alemão, ao menos não enquanto a compreensão não for introduzida expressamente como compreensão de "sentido". Se, contudo, quisermos servir-nos dessa palavra que adquiriu foros de cidadania também no século XIX, uma outra descoberta também se revela inevitável: o "sentido" sempre é algo espiritual.

\section{Sobre o conceito das Ciências do Espírito}

(1) Por conseguinte, a distinção expressa em uma dualidade de Ciências Naturais e Ciências do Espírito não é nenhum ponto de partida confiável, estável. Muito pelo contrário, ela designa um estado claramente frágil, que poderia ser alterado pelo acréscimo de novas culturas, que não desenvolveram analogamente essa dualidade, em benefício de uma concepção unitária da ciência. Existe, porém, um outro problema prioritário: supor a estrutura dual do cosmos das ciências ainda não significa compreendê-la como dualidade de Ciências Naturais e Ciências do Espírito. Como sucessoras das "Ciências do Espírito", que ocasionalmente se afiguram antiquadas, oferecem-se, e.g., as "Ciências da Cultura" ou as "Ciências Sociais". Não seria, justamente com vistas à globalização, mais adequado perguntar pela relação de "Ciências Naturais" e "Ciências da Cultura" ou "Ciências Sociais" - ou mesmo pela relação entre as Ciências Naturais e as "humanidades" ["humanities"]? Não quero dizer aqui nada sobre o infeliz termo "humanidades", e "Ciências Sociais" não é um conceito adequado para suceder às "Ciências do Espírito". No entanto, a dualidade de "Ciências Naturais" e "Ciências da Cultura" tem uma certa plausibilidade, se compreendermos "natureza" e "cultura" como os dois objetos que esgotam a totalidade dos objetos possíveis das ciências. Mas justamente esse paralelismo de dois objetos distintos reduz o sentido originário do termo "Ciências do Espírito" pelo seu aspecto decisivo. Preciso explanar brevemente essa afirmação - e quero fazê-lo com uma defesa do uso do termo "Ciências do Espírito".

(2) As "Ciências do Espírito" são as ciências do "espírito", mas o que é o "espírito? Muitos parecem ter dificuldades com o termo alemão "espírito". Ele não se insere bem na discussão internacional, além disso ele permite associações varia- 
das - e sobretudo desconfortáveis: no pior caso, o "anti-espírito" [Ungeist] da assim chamada "via especial da Alemanha", no mínimo o ancoramento em uma época metafísica já superada, em cujo fundo um dualismo ontológico tradicional de "natureza" e "espírito" ainda produz confusão. No entanto, podemos, com vistas aos nossos fins, contornar essa pergunta certamente difícil, pois a especificidade das "Ciências do Espírito" pode ser apreendida também sem uma resposta à referida pergunta. Quero tentar fazer isso da perspectiva da filosofia alemã clássica: a própria contraposição de Ciências da Natureza e Ciências do Espírito, no sentido de uma disjunção integral, ainda tem as suas raízes nessa tradição. Ao menos ela pertence aos pressupostos dessa cultura científica dual, mais próximos em termos de história da consciência. Com isso, a minha tentativa talvez seja um tanto vinculada à tradição - mas não necessariamente deverá malograr por esse motivo. Muito pelo contrário, ela pode, precisamente por ser algo 'indigesta', motivar ao raciocínio, e isso especialmente em uma época na qual, por outro lado, se procura contrapor, em discursos festivos, ao palavreado permanente sobre a "crise" das Ciências do Espírito o palavreado sobre as estatísticas impressionantes de visitantes a exposições, museus e festivais de música - como se a verdadeira crise de uma ciência pudesse ser desfeita pela discurseira sobre a cultura do evento e a venda de ingressos monitorada pela mídia.

As Ciências do Espírito são as ciências sobre o "espírito" e este é, num primeiro momento, aquela realidade que se revela sem mediações no ser humano, enquanto "ser espiritual", nos seus sentimentos, nas suas idéias e nos seus atos de vontade, isto é, em suas "atividades espirituais" (não importa qual seja o fundamento material das mesmas). Num segundo momento, o "espírito" é igualmente aquela realidade que tem por base imprescindível a atividade desse "espírito" e é criado tão-somente por essa base e configurado num 'mundo' à parte ou, melhor dito, em 'mundos' à parte: nos universos da sociedade e do direito, da linguagem, da arte, da religião, da ciência e da filosofia. Diferentemente do que na "Ciência Natural", o "espírito" aparece duas vezes na "Ciência do Espírito" - a primeira vez do lado dos sujeitos que trabalham como cientistas, a segunda vez do lado dos "objetos" dessa ciência, pois esses são ou a própria atividade espiritual ou os resultados da mesma. As Ciências do Espírito são, por conseguinte, aquelas ciências nas quais "seres espirituais" fazem de produções da atividade espiritual o objeto do conhecimento. A sua especificidade é uma relação do espírito consigo mesmo: nelas o "espírito" sabe acerca do "espírito". Isso naturalmente não se altera, se falarmos de "Ciências da Cultura" em vez de "Ciências do Espírito" mas a referência a si mesmo, nesse caso, não é elevada ao plano da consciência já na terminologia. Para o espírito cognoscente, a "cultura" se afigura como objeto exterior, não diferentemente da "natureza". Mas justamente com isso se ignora a relação consigo mesmo, que perfaz o traço característico das Ciências do Espírito e condiciona a sua forma específica de desenvolvimento: nas Ciências do Espírito, o conhecimento do objeto precisamente não é um mero conhecimento do objeto, mas, ao mesmo tempo, sempre um conhecimento de si mesmo. Por isso o sujeito cognoscente sempre se transforma no decurso do processo de conhecimento do 
seu objeto. No conhecimento próprio das Ciências do Espírito, o sujeito sempre está também referido a si mesmo - mesmo se ele não reflete sobre esse fato, não tem nenhuma consciência dele e crê estar lidando com um objeto que lhe é exterior.

(3) As Ciências do Espírito são ciências do autoconhecimento do espírito, ciências, nas quais o espírito está referido, simultaneamente, à sua referência a outros objetos, a si mesmo e conhece a si mesmo. Nisso reside a sua especificidade; e a "compreensão", enquanto conceito de método das Ciências do Espírito, também pode ser pela primeira vez compreendida como conceito de método das Ciências do Espírito: a sua compreensão do sentido é uma compreensão de si mesma - e uma Hermenêutica que não inscreve esse aspecto da auto-referência no conceito da compreensão deverá torturar-se debalde no trabalho da diferença alegadamente tão importante e já lingüisticamente tão pouco nítida entre "explanação" e "compreensão".

Para as Ciências do Espírito, essa "compreensão do sentido" é fundamental. Todas elas estão sujeitas ao imperativo que encima a entrada do templo de Apolo em Delfos: "Conhece-te a ti mesmo!" Sabe-se, contudo, que esse imperativo deve ser compreendido de diversos modos. Ele é tanto um convite à evocação da dimensão divina no ser humano quanto uma lembrança da nossa própria contingência, finitude e transitoriedade. A compreensão de nós mesmos, à qual as Ciências do Espírito permitem aceder, é uma compreensão da natureza espiritual do ser humano - da sua grandeza, mas também da sua indigência e fraqueza, da elaboração dos seus sentimentos, da sua vinculação temporal e especial, bem como do conhecimento, mediante o qual ele supera essa vinculação, dissolvendo todas as limitações em si e entrando em diálogo com pessoas muito distantes e há muito tempo passadas. As Ciências do Espírito dão acesso ao material para uma análise de todos os produtos do espírito; elas apresentam também todas as figuras da sua autocompreensão - para si mesmo e na relação com a natureza, com outras pessoas e talvez também com os deuses, ou também no ato da sua recusa.

Sobretudo elas dão acesso a um traço fundamental da vida espiritual: à historicidade do espírito. Por isso não é um acaso que a sua conceitualização coincida com a fase inicial da constituição das Ciências do Espírito, a época ao redor de 1800, quando ela é formulada por Hegel de forma concisa, mas penetrante, nos seguintes termos: "o que nós somos, somos ao mesmo tempo historicamente". Mas, se somos ao mesmo tempo historicamente o que somos, esse conhecimento acerca de nós deve ser simultaneamente um conhecimento histórico. Por isso, as Ciências do Espírito são, em ampla medida, ciências históricas, e como tais elas são a "memória cultural" do espaço cultural que é o seu respectivo objeto, por elas preservado e analisado. Quero, porém, derivar da frase recém-citada ainda uma segunda deixa, a da "identidade". Se somos ao mesmo tempo historicamente o

2 Hegel. Vorlesungen über die Geschichte der Philosophie. 1ª Parte. Introdução à história da filosofia (1823), in: Hegel. Vorlesungen. Ausgewählte Nachschriften und Manuskripte. Edd. Pierre Garniron e Walter Jaeschke. Vol. 6. Hamburgo, 1994, p. 6. 
que somos, essa dimensão histórica é um momento constitutivo da nossa identidade. Por meio da nossa história, nos tornamos o que somos - não no sentido de que somos um mero produto do passado, mas no sentido de que não seríamos o que somos sem esse passado. Isso pode ser mostrado em vários planos, até ao nexo entre a percepção e a memória - e diante do conhecimento socialmente produzido falta a hipótese, segundo a qual essa relação entre espiritualidade e historicidade novamente se altere e ceda lugar a uma época de "a-historicidade", não tem muita plausibilidade.

(4) Justamente enquanto ciências históricas, as Ciências do Espírito contribuem ao desenvolvimento da identidade - tanto da do indivíduo quanto da de comunidades maiores e povos. Afinal de contas, a "identidade" não é nada de imediato; forma-se a partir de si mesma ou é instaurada conscientemente. Mas essa formação da identidade não é efetuada já pelo recurso ao passado; é monitorada por atos de seleção, também de seleção consciente. Nesse processo de seleção, as Ciências do Espírito desempenham um papel decisivo - mediante o esquecimento intencional do passado, mediante a sua exclusão, mas também mediante o resgate do passado, mediante a sua inclusão na elaboração de um cânone do conhecimento - mas também mediante a construção de passados, por meio da exclusão e idealização, por meio da inversão ideológica do princípio da historicidade: se somos historicamente o que somos, é também plausível que preparemos e asseguremos, de modo igualmente histórico, o que queremos ou devemos ser isto é, que retroprojetemos isso ao passado. Mas esse é apenas um desagradável caso limítrofe das Ciências do Espírito, que devem, entre outras tarefas nada menores, contra-arrestar tais desenvolvimentos falhos. As Ciências do Espírito sempre participam em dupla função do processo de formação da identidade: são sujeitos desse processo, ainda que este muitas vezes se desenrole, sem chamar a atenção, por assim dizer naturalmente - e têm simultaneamente a tarefa de refleti-lo.

\section{Sob as condições da globalização}

(1) Depois dessa preparação, sobretudo sobre o conceito das Ciências do Espírito, talvez um pouco extensa, mas provavelmente não-supérflua, quero agora entrar no tema propriamente dito: que efeitos a globalização produz nas Ciências Naturais e nas Ciências do Espírito, bem como na relação entre elas? A resposta a essa pergunta é prejudicada por uma dupla dificuldade. Em primeiro lugar, tal resposta ainda não pode partir de uma base empírica segura, mas terá, necessária e essencialmente, um caráter prognóstico. Diferente seria a situação no caso da "europeização", mas esta transcorre segundo outras regras e também não apresenta os conflitos que se manifestam da "globalização". Em segundo lugar, a separação profunda das duas culturas científicas em pauta, raras vezes superada, tem por conseqüência que a resposta só pode ser dada a partir da perspectiva de uma das duas ciências, das Ciências do Espírito. A sua segunda parte, atinente às Ciências Naturais, tem antes o estatuto de uma suposição formulada a partir de uma perspectiva externa. 
(2) Mas antes de entrar no tema propriamente dito, quero ainda fazer uma observação de caráter geral. Por motivos plausíveis, a globalização não altera em nada a determinação das Ciências Naturais e das Ciências do Espírito, e, nesse sentido, também não altera em nada a formulação conceitual da relação entre as mesmas. Mas ela produz um efeito fático: desloca o desequilíbrio de qualquer modo existente entre as Ciências Naturais e as Ciências do Espírito, em ampla medida em desvantagem das últimas - e isso, apesar da existência de boas razões para um encaminhamento contrário. Vejo, para tal fim, duas razões distintas, embora interligadas. A primeira reside no estado total ou amplamente deficitário das Ciências do Espírito, num grande número de outras culturas. Se quiséssemos representar cartograficamente a difusão das Ciências Naturais e das Ciências do Espírito, o mapa das últimas apresentaria um número bem maior de lacunas do que o das primeiras. Sob essa condição, a globalização das Ciências Naturais não importa se desejada ou não - pode ser impulsionada com facilidade consideravelmente maior do que a das Ciências do Espírito, que, em muitos lugares, carece dos pontos de apoio. Mas essa ausência de fato das Ciências do Espírito possui uma razão mais profunda, o que me conduz ao meu segundo ponto.

Mesmo se, na cultura européia dos primórdios da Idade Moderna, as Ciências Naturais e as Ciências do Espírito começam a desenvolver e separar-se mais ou menos na mesma época, com um ligeiro atraso das Ciências do Espírito, sendo, assim, na sua forma atual de manifestação, por assim dizer, um produto gêmeo "de um só espírito" (como já o foram, de resto, as suas formas anteriores na Antigüidade): o limiar de aceitação para as Ciências Naturais é bem mais baixo, no processo da globalização, do que o limiar de aceitação para as Ciências do Espírito. Tudo indica que isso tem menos a ver com o conceito de ciência do que com os objetos de ambas as ciências, a "natureza" e o "espírito". Não há dúvida de que não podemos nos entregar à ilusão de que a "natureza" aqui tem, por assim dizer, uma preferência inata, porque seria algo simplesmente dado e acessível, pois tal ingenuidade fica excluída já pela longa e tortuosa história do conceito de natureza, ainda nos primórdios da Idade Moderna. É sabido - e só preciso lembrar isso nesse contexto - quão penoso foi o processo de desencantamento, do qual a "natureza" saiu como objeto coisificado que revelou ser apto para constituir o objeto de uma ciência, cujo interesse supremo foi o da confiabilidade e calculabilidade do seu objeto: isso pertence apenas à fase tardia do processo europeu de racionalização, que encontrou a sua expressão conclusiva no Iluminismo.

Apesar dessa história repleta de tensões, a recepção de tal conceito de natureza não parece representar nenhum problema enquanto pressuposto da ciência, no processo da globalização. Diversa é a situação das Ciências do Espírito: mormente o conceito do seu objeto, o conceito do espírito, parece estar enraizado consideravelmente mais na especificidade, sendo assim, comparativamente, "resistente à globalização". Por um lado, encontramos fora das tradições culturais da Europa uma conformação amplamente análoga do direito e do Estado, da arte e, sobretudo, da religião. Por outro lado, parece que não encontramos na mesma escala a tendência de tornar tais produções objeto de um conhecimento científico 
livre, pelo qual a auto-referência fática ou consciente é produzida de modo mediado e, conseqüentemente, potenciado.

(3) Por esse motivo, a globalização parece-me produzir efeitos claramente distintos para as Ciências Naturais e as Ciências do Espírito. No tocante às primeiras, quero externar aqui, com a devida cautela, a minha impressão de que elas só são exteriormente afetadas pela globalização. Quero dizer, com isso, que a globalização não diz respeito ao seu objeto, à "natureza", no sentido mais amplo do termo, e tampouco aos seus métodos. Na sua fase atual, uma ampliação imaginável do seu campo de objetos também me parece desempenhar um papel quando muito marginal. A exploração de objetos do conhecimento, no âmbito global, já ocorreu há muito tempo, antes da globalização atual, primacialmente econômica - já no século XVIII e, depois, naturalmente no século XIX: nesse quadrante do mundo, o nome de Alexander von Humboldt não é desconhecido. Essa exploração de objetos do conhecimento, no âmbito global, indubitavelmente continuará - mas ela não tem nada a ver com o fenômeno da globalização.

Por esse motivo, parece-me que os novos problemas advenientes da globalização para as Ciências Naturais deveriam ser mais apropriadamente correlacionados à idéia da "organização da ciência". Uma ciência que não é nem aprisionada por fronteiras políticas nem por fronteiras de um espaço cultural, mas operada num âmbito global, carece urgentemente de tal organização - mais especificamente, de uma "organização de baixo para cima". Deve desenvolver procedimentos da divisão internacional do trabalho e de uma cooperação igualmente internacional, e deve desenvolver formas para uma participação de todos na distribuição dos resultados da pesquisa, de formas para o intercâmbio de resultados, para a transmissão e distribuição do conhecimento - e deve também desenvolver uma linguagem científica internacional para a comunicação, hoje do mesmo modo como há dois mil anos, no período helenístico. Essas tarefas, sem dúvida, são importantes e a sua realização demanda muita energia - mas elas não me parecem conter nenhum problema sobre o qual deveria pronunciar-me no contexto do tema que me foi dado.

(4) A situação é inteiramente distinta para as Ciências do Espírito. Sabe-se genericamente que elas não podem concorrer com as Ciências Naturais, sob o ponto de vista da extração de benefícios econômicos, o que explica a estima apenas reduzida, da qual elas gozam - na era dos mecanismos de coação econômica (cuja culpa deve ser imputada aos próprios homens) - na opinião pública, à qual a extração de benefícios econômicos diretos freqüentemente se afigura como único critério de valor. Em contrapartida, as colegas e os colegas das Ciências Naturais só conseguem reprimir, com dificuldade, a sua suspeita contra o caráter científico de atividades que podem ser executadas sem instalações para pesquisa em grande porte, que não estão organizados em equipes de pesquisadores e distribuem as tarefas segundo o princípio da divisão do trabalho e 
para os quais a escrivaninha e uma biblioteca constituem os recursos mais importantes. E antes já mencionei que as Ciências do Espírito continuam perdendo em importância diante das Ciências Naturais, que atuam no âmbito global. Apesar disso, justamente as Ciências do Espírito se vêem afetadas e desafiadas de múltiplas maneiras pela globalização.

(a) Quero abordar esses desafios em quatro perspectivas e inicio com a primeira, mais abrangente: A própria globalização se transforma no tema das Ciências do Espírito, pois não é, nem no sentido mais genérico imaginável, um fenômeno pertencente à "natureza", mas sim à Lebenswelt, ao mundo vivido dos seres humanos, cuja investigação é da competência das Ciências do Espírito. Aqui a Economia e o Direito naturalmente desempenham um papel especial. Não quero arrogar-me o papel de um colega dessas disciplinas, razão pela qual também não posso entrar em detalhes, mas não creio enfrentar uma contestação fundamentada pelos representantes dessas disciplinas, ao afirmar que a globalização nos coloca perante desafios inteiramente novos. Esses desafios já se revelam em uma área secundária da dimensão econômica da atividade das organizações não-governamentais (ONGs). Em combinação com eles, deparamo-nos com questões importantes referentes à relação entre Economia e Ecologia, mas também à relação entre Ecologia e responsabilidade social - quer dizer, em última análise, com questões de ética da Economia (em combinação com ética do meio ambiente) e com questões de Direito Econômico. A Ciência jurídica de qualquer modo se vê chamada à responsabilidade, similarmente à Ciência Econômica. Menciono, a título exemplificativo, apenas as questões de Direito de Família, Direito das Religiões e o Staatskirchenrecht, o Direito que regulamenta as relações entre o Estado e as Igrejas. Diante da globalização, as conhecidas perguntas do Direito que regulamenta as relações entre os Estados ganham uma nova dimensão, e as questões do "Direito Internacional Público" e do "Direito Cosmopolita" não mais podem ser comprimidas em duas breves partes da Filosofia do Direito, que seguem o capítulo sobre o "Direito de Estado", conforme ocorre na "Teoria/Doutrina do Direito" de Kant ou mesmo num "Apêndice" sobre o "Direito Natural" em Fichte. ${ }^{3}$ Somente sob as condições da desgraça global [globales Unheil],* o Direito Internacional Público foi colocado em fundamentos inteiramente novos: o lugar do enfoque individualista do ius gentium ou Direito Internacional Público clássico, que busca construir o ordenamento jurídico abrangente a partir dos povos individuais (e fracassa nesse empenho), foi assumido pelo enfoque universalista, a assunção do primado de um ordenamento jurídico universal, cuja vigência independe do reconhecimento expresso dos Estados que lhe estão sujeitados.

3 Kant, Metaphysische Anfangsgründe der Rechtslehre. AA VI.343-355, ou Fichte, Grundlage des Naturrechts. 2. Teil: Angewandtes Naturrecht. 2. Anhang, in: Fichte, Obras Completas. Seção I, vol. 4, pp. 151-165.

* Possível alusão ao segundo período do primeiro capítulo da Dialektik der Aufklärung (1947), de Max Horkheimer e Theodor W. Adorno: "[...] die vollends aufgeklärte Erde erstrahlt im Zeichen triumphalen Unheils" (citado pela edição de 1969, Frankfurt/Main, S. Fischer, p. 9) [nota do Tradutor]. 
(b) Talvez menos chamativamente, mas não com menor gravidade para a formulação das tarefas das Ciências do Espírito, seja outro aspecto mais atinente às Ciências do Espírito que procedem segundo o método histórico-filológico. Principio com uma perspectiva 'quantitativa', com o aumento enorme das fontes a serem retrabalhadas pelas Ciências do Espírito. Na era da globalização, estas últimas se deparam com uma multiplicidade de línguas e tradições históricas, de formas artísticas e religiões. Pelo que vejo, essa ampliação possui aqui um caráter claramente distinto do campo das Ciências Naturais. Aqui não importa para as Ciências do Espírito desenvolver e implementar efetivamente uma linguagem científica e formas de organização, mas a garantia e exploração de um sem-número de fontes. Já nisso há um desafio ingente e hoje quase não mais abordável em perspectiva panorâmica. E esse desafio se dirige aos espaços culturais nos quais as Ciências do Espírito estão estabelecidas. Assim, como elas assumiram até agora essa tarefa para todas as culturas do Velho Mundo, elas precisam, agora, assumir adicionalmente essa tarefa para um grande número de outras tradições culturais, nas quais elas não são um momento integral da cultura do modo que nos é familiar - e elas não podem assumir essa tarefa em troca da retrospectiva sobre o Velho Mundo, mas adicionalmente. E é evidente que esse desafio não se coloca apenas para as Ciências do Espírito, de orientação primacialmente histórica, mas também para as Ciências do Espírito de orientação sociológica - da Sociologia à Etnologia.

(c) Mas o problema antes esboçado não é de natureza meramente quantitativa. Justamente devido à extensão de novas fontes e objetos de pesquisa, o aspecto qualitativo não é menos importante: a era da globalização formula exigências muito elevadas ao trabalho de seleção empreendido pelas Ciências do Espírito, especialmente às Ciências Históricas. Essa tarefa de seleção é, por assim dizer, o "irmão gêmeo menor" das Ciências Históricas. Ela deve ser cumprida, para que as Ciências do Espírito não impeçam o cumprimento da sua tarefa, do autoconhecimento do espírito mediante o conhecimento das produções espirituais, por causa da pura e simples quantidade dos materiais de pesquisa. Na era da globalização, os temores articulados por Nietzsche, já há um século e meio, com referência às "Vantagens e desvantagens da Historiografia para a vida", têm um significado não apenas igual, mas ainda consideravelmente maior do que na época de Nietzsche. As tarefas da seleção, da acentuação, inclusive da formação do cânone, assumidas hoje pelas Ciências do Espírito, com vistas à cultura européia, devem ser cumpridas hoje por elas em escala global. Mas o critério dessa seleção não pode ser outro senão a tarefa das Ciências do Espírito em geral: a autocompreensão do espírito humano.

(d) Ocorre que a tarefa da seleção toca um ponto delicado: ela formula um juízo qualitativo sobre as tradições de outras culturas, pois o encontro com elas não se processa apenas no plano de um intercâmbio do conhecimento, realizado em clima amistoso entre colegas, mas claramente também na forma de um conflito entre as culturas. A seleção aborda o problema da formação da identidade, que mencionei antes como tarefa importante das Ciências do Espírito. Dito em outros termos: o contato entre as culturas, a sua interação pacífica, mas também o seu 
entrechoque parcial e, talvez, até a sua luta entre si são uma tarefa exclusiva das Ciências do Espírito - e todos conhecemos o potencial e riscos que nos espreitam aqui. Esse trabalho tem um significado tão decisivo, por tratar de um problema decisivamente importante da vida espiritual, da identidade. E ele é tão difícil, porque não pode ser realizado num plano estabelecido - no do intercâmbio científico ou também do debate científico. Afinal de contas, o meio "ciência" - e especialmente o meio "Ciência do Espírito" - não são aceitos em todos os lugares como interlocutores. Não obstante, somente a Ciência do Espírito - e agora também especialmente a filosofia, à medida que queiramos subsumi-la às "Ciências do Espírito" - pode enfrentar essa tarefa, conduzir o diálogo necessário e, caso ele seja rejeitado, colocar no seu lugar, à guisa de substituição, a pesquisa unilateral. Ela deve também assumir essa tarefa diante de sociedades que não obtêm a sua identidade por intermédio de uma auto-referência espiritual cientificamente mediada, mas, e.g., por intermédio da religião. E ela deve tentar relativizar pretensões particulares de fundamentação - também as próprias! - e trabalhar na contracorrente na formulação de convicções não-contingentes que se prestem a elaborar ao menos um mínimo de pressupostos comuns que assegurem os fundamentos de um convívio.

Não quero de modo nenhum subestimar as tarefas enfrentadas pelas Ciências Naturais, uma vez que não posso emitir nenhum juízo competente sobre elas. Apesar disso, penso que as tarefas acarretadas pela era da globalização dizem respeito especialmente às Ciências do Espírito - e essas tarefas são de grande envergadura. Dentre as condições não especialmente favoráveis, sob as quais elas trabalham atualmente, elas devem definir os contornos da sua autocompreensão e buscar ao mesmo tempo o diálogo com todas as outras culturas, a fim de elevarem à consciência da sociedade a contribuição das mesmas para a consecução do objetivo comum e com isso preparar simultaneamente a solução de problemas práticos. 